\title{
Simultaneous Optimal Placement and Sizing of DSTATCOM and Parallel Capacitors in Distribution Networks Using Multi-Objective PSO
}

\author{
Arash Zeinalzadeh \\ North Khorasan Electric Distribution \\ Company \\ Bojnourd, Iran
}

\author{
Abouzar Estebsari \\ Department of Energy \\ Politecnico di Torino \\ Turin, Italy
}

\author{
Alireza Bahmanyar \\ Department of Electrical Engineering \\ Iran University of Science and \\ Technology \\ Tehran, Iran
}

\begin{abstract}
The increase in electricity demands has increased the dimension and loading of today radial distribution feeders, which in turn would result in more losses and voltage drops. Such issues together with the demand for higher power quality has raised a need for modern power system management techniques such as using power electronic devices. Among, DSTATCOM is introduced as an effective solution for reactive power control in power distribution level. To make a better use of DSTATCOM in improving the network power quality, it should be sized and placed in accordance with parallel capacitors. A multi-objective optimization method is proposed in this paper to find the optimal location and size of DSTATCOM and parallel capacitors simultaneously. The cost of power losses, voltage profile and voltage stability are selected as objectives to be improved. The obtained results on the IEEE 33-node test system indicate that the proposed method satisfies the defined objectives and considerably improves the network operational characteristics.
\end{abstract}

Index Terms--Distribution system, DSTATCOM, MOPSO, Optimization, Parallel capacitors.

\section{INTRODUCTION}

The increased demand for electricity has increased the loading and the size of today distribution networks. Considering the radial nature of distribution feeders, the increase in loading results in more voltage drop and power losses. Consequently, a large portion of power system losses are from the distribution level. Leveraging new technologies to improve voltage profile of power systems avoids load shedding which is techno-economically undesired [1].

The development in fast and reliable semiconductor switching devices and the advances in power electronics has led to an increase in their integration in all levels of today power systems. Among, DSTATCOM (Distribution Static COMpensator) can provide a cost-effective solution for compensation of reactive power and improving the power quality of electrical power distribution systems. DSTATCOM is a voltage source converter (VSC)-based power electronic device, supported by short-term energy stored in a dc capacitor [2]. It mainly consists of a DC energy storage device, a VSC that converts the dc voltage across the storage device into three-phase AC output, a controller and a coupling transformer.

If properly utilized, DSTATCOM can cancel the effect of poor load power factor, the effect of harmonic contents in loads, the effect of unbalanced loads and the dc offset in loads [2]. Optimal placement and sizing of DSTATCOM considerably influences its success in fulfilling the mentioned tasks. Therefore, some previous studies have considered this problem and have proposed solutions.

The method proposed in [3] considers the reduction in power losses and line currents together with the voltage profile as the objective function and use an immune algorithm to search for the optimal DSTATCOM placement. In [4] authors employ a Fuzzy-ACO algorithm for simultaneous reconfiguration, optimal placement of DSTATCOM, and photovoltaic array in a distribution system. The authors of [5][8] also propose methods for optimal sizing and placement for distributed generation units and DSTATCOM in a distribution network.

The Firefly algorithm is employed in [9] to find the optimal location of DSTATCOM to decrease power losses and harmonic distortions and to improve voltage levels. Analytical approaches are proposed in [10],[11] to solve the optimal placement problem. In [12] authors propose the use of a hybrid Genetic and Ant Colony algorithm to reduce network losses. The authors of [13] solve the DSTATCOM allocation problem considering network reconfiguration using a combination of BB-BC and Genetic algorithms. In [14] a Bat algorithm is employed to find the optimal location considering network loads variations. Despite the various previous research works performed for optimal placement of DSTATCOM, none of these studies consider the simultaneous 
optimal placement and sizing of DSTATCOM and parallel capacitors in distribution networks [15].

Optimal placement and sizing of DSTTCOM in accordance with parallel capacitors, considerably influences its success in improving the network power quality. Parallel capacitors cannot provide a flexible compensation considering the variation in distribution system loads. On the other hand, DSTATCOM requires much more investment. Therefore, a combination of parallel capacitors and a limited number of DSTATCOM units can provide the required flexibility with an affordable cost.

In this paper, the cost of power losses, voltage profile and voltage stability are selected as objectives. Our studies show that the simultaneous placement and sizing of capacitors and DSTATCOM can considerably improve the considered objective functions. A MOPSO (Multi-Objective Particle Swarm Optimization) is employed to solve the problem and the tests performed on the IEEE 33-node test system verify the effectiveness of the proposed method.

\section{PROBLEM FORMULATION}

In this paper, three technical objectives are considered for DSTATCOM sizing and placement: lower power losses, better voltage profile and improved voltage stability. Therefore, the considered objective function is a multiobjective function:

$$
\min F=\left[f_{1}, f_{2}, f_{3}\right]
$$

The objective function $f_{l}$ is defined as:

$$
f_{1}=P_{\text {loss }}
$$

where $P_{\text {loss }}$ denotes the active power losses.

The objective function $f_{2}$ is a voltage deviation index defined as:

$$
f_{2}=\sum_{i=1}^{N}\left(\begin{array}{ll}
V_{i} & V_{\text {rated }}
\end{array}\right)^{2}
$$

where $N$ is the number of network node.

The objective function $f_{3}$ is a voltage stability index proposed in [16]. The equations for evaluation of this index are based on power flow [17]. Consider the simple 2-node network of Fig. 1. The stability index for this simple feeder can be calculated as follows:

$$
S I\left(n_{2}\right)=\left|V_{1}\right|^{4} \quad 4\left[P_{2} R_{1}+Q_{2} X_{1}\right] V_{1} \mid \quad 4\left[P_{2} R_{1}+Q_{2} X_{1}\right]^{2}
$$

where $n_{1}, n_{2}, V_{1}, V_{2}$ are sending and receiving nodes and their voltages respectively, $P_{2}$ and $Q_{2}$ are node 2 net active and reactive power, $R_{l}$ and $X_{l}$ are line resistance and reactance and $I_{L}$ is the line current.

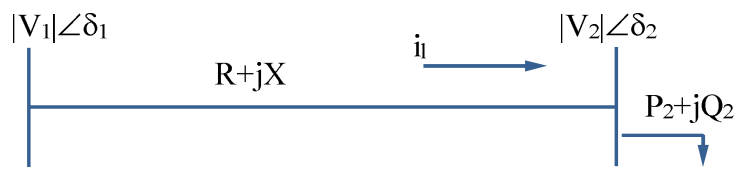

Figure 1. A distribution network branch

Considering the voltage stability index equation, the objective function $f_{3}$ is defined as:

$$
\begin{gathered}
f_{3}=\frac{1}{f_{3}^{\prime}} \\
f_{3}^{\prime}=\min \left(S I\left(n_{i}\right)\right), i=1,2, \ldots . N
\end{gathered}
$$

where $N$ is the number of network nodes.

\section{A. DSTATCOM constraints}

The considered constraints for DSTATCOM are as follows:

$$
\begin{gathered}
0.9 p u \leq V_{n} \leq 1.1 p u \\
0 \leq Q_{\text {DSTATCOM }} \leq 5000 \mathrm{KVAR} \\
0 \leq I_{\max } \leq 400 \mathrm{~A}
\end{gathered}
$$

where $Q_{\text {DSTATCOM }}$ and $I_{\max }$ are the DSTATCOM reactive power and the maximum current of network branches.

\section{B. Capacitors constraints}

In practice, the parallel capacitors are composed of a group of several identical capacitors interconnected. Therefore, the capacity of a parallel capacitor is an integral multiple of a minimum base value:

$$
Q_{c i}=L Q_{0}
$$

where $Q_{0}$ is the minimum base capacitance.

Due to economic considerations, the overall capacitance of the capacitors connected to a node is also limited:

$$
\sum Q_{c i} \leq Q_{t}
$$

where $Q_{t}$ is the reactive power limit.

In this paper the considered minimum base capacitance is $150 \mathrm{KVAR}$ and the maximum considered number of capacitances at each node is 15 .

\section{DSTATCOM LOAD FLOW MODEL}

In this paper, the well-known backward forward sweep method is employed for distribution load flow. For the simple 
two node network of Fig. 2, the following equation can be written:

$$
V_{j} \angle \alpha=V_{i} \angle \delta \quad Z I_{L} \angle \theta
$$

where, as shown in Fig. 2, $V_{i}, V_{j}, \alpha$ and $\delta$ are the voltages and their phase angles at the beginning and the end of the linesection, respectively. $Z$ is the line impedance, $I_{L}$ is the line current and $\theta$ denotes its phase angle.

After installation of the DSTATCOM at node $j$, as shown in the phasor diagram of Fig. 3, the equations change to the following form:

$$
\begin{gathered}
V_{\text {jnew }} \angle \alpha_{\text {new }}=V_{i}^{\prime} \angle \delta^{\prime} \quad(R+j X) I_{L}^{\prime} \angle \theta \\
\left.(R+j X) I_{\text {DSTATCOM }} \angle \alpha_{\text {new }}+\pi / 2\right)
\end{gathered}
$$

Therefore, the injected reactive power can be calculated as follows:

$$
\begin{gathered}
j Q_{\text {DSTATCOM }}=V_{\text {jnew }} I_{\text {DSTATCOM }} \\
\angle I_{\text {DSTATCOM }}=\frac{\pi}{2}+\alpha_{\text {new }}, \alpha_{\text {new }} \prec 0
\end{gathered}
$$

where $\alpha_{\text {new }}$ is the modified phase angle of the compensated node, which will be calculated using the above equations in load flow iterations [18].

\section{A. Optimization algorithm}

Particle swarm optimization (PSO) is a population based stochastic optimization algorithm inspired by sociological behavior associated with bird flocking or fish schooling. The PSO is comprised of a set of particles moving around the search space where the position of each particle is adjusted according to its own experience and that of its neighbors. Let $f_{i}$ and $x_{i}$ denote the objective function and the position of particle $i$ in the search space changing with velocity $v_{i}$. The particle's personal best position denoted by $x^{i, b e s}$ refers to the position with the best value of the objective function $f^{\text {t, bes }}$. The best position found over the whole swarm $x_{g, b e s}$ can be found by comparing all the $f^{i, b e s}$ for all particles. Let $f^{g}$,bes denote the objective function for $x^{g \text {,bes }}$.

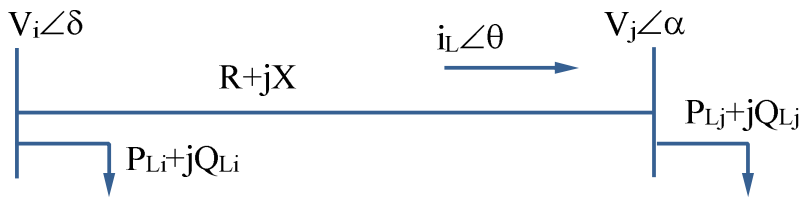

Figure 2. A simple two node network

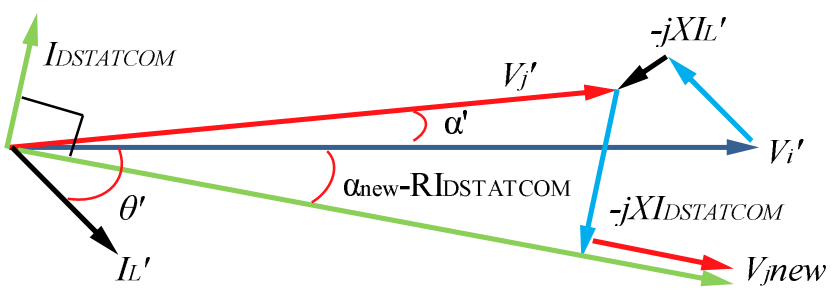

Figure 3. Phasor diagram after DSTATCOM installation

The positions and velocities of particles are initialized randomly. As the algorithm proceeds, at each step $\mathrm{t}+1$, the velocities and positions are updated using the previous step values as follows:

$$
\begin{aligned}
& v_{j}^{i}[t+1]=w v_{j}^{i}[t]+c_{1} r_{1}\left(x_{j}^{i, b e s}[t] \quad x_{j}^{i}[t]\right) \\
& +c_{2} r_{2}\left(x_{j}^{g, b e s}[t] \quad x_{j}^{i}[t]\right)
\end{aligned}
$$

$$
x_{j}^{i}[t+1]=x_{j}^{i}[t]+v_{j}^{i}[t+1]
$$

where $w$ is the inertia coefficient $r_{1}$ and $r_{2}$ are random values in the range $[0,1]$ with uniform distribution and $c_{l}$ and $c_{2}$ are positive acceleration constants.

\section{B. MOPSO algorithm}

The multi-objective PSO proposed in 2004, is employed for simultaneous optimization of multiple objective functions [19]. In this algorithm, the vector $x *$ is Pareto optimal if there is no other feasible vector which would decrease some criterion without causing an increase in other criterions. The set of optimal solutions of the MOPSO composed of nondominated solutions is known as the Pareto front. The vector $x_{1}$ is said to dominate $x_{2}$ (denoted by $x_{1} \leq x_{2}$ ), if $x_{1}$ is not worse than $x_{2}$ for any of the functions and it is better for at least one function:

$$
\begin{aligned}
& \forall i \in\left\{1,2, \ldots, N_{o b j}\right\}: f_{i}\left(x_{1}\right) \leq f_{i}\left(x_{2}\right) \\
& \exists j \in\left\{1,2, \ldots, N_{o b j}\right\}: f_{i}\left(x_{1}\right)<f_{i}\left(x_{2}\right)
\end{aligned}
$$

The algorithm steps are as follows:

1. Initial population generation: At the first step, particles are initialized with random positions and velocities. In the considered case, the size and location of DSTATCOM and capacitors are generated in form of vectors as algorithm particles. The DSTATCOM reactive power is considered as a continuous variable. The considered capacitance is an integral multiple of the minimum base value. The locations of DSTATCOM and capacitors are positive integers.

2. Load flow and calculation of objective functions.

3. Determine the non-dominated solutions.

4. Store the non-dominated solutions in a repository. 
5. Use the equations to update each particle. Considering that we have a set of optimal solutions, a leader should be chosen for each particle. In this step, the best position of each particle should be updated by comparing the new position to the best global position of each particle and selecting the dominant one as the new position. If none of them dominates, one will be chosen randomly.

6. In this step, the best position of each particle should be updated by comparing the new position to the best global position of each particle and selecting the dominant one as the new position. If none of them dominates, one will be chosen randomly.

7. After updating all the particles, store the non-dominated members of the current population in the repository.

8. Investigate the repository. Remove the dominated solution and keep the non-dominated solutions.

9. If the repository gets full, remove the extra solutions.

10. If the algorithm converges, the optimization process is over. Otherwise, go to step 5.

11. If the optimization process is over, select the nondominated population as the Pareto front.

The Pareto front is composed of a number of optimal solutions. The distribution system designers and operators should select the final solution based on their knowledge and their requirements. Due to the inherent uncertainty in operators' decision, the fuzzy compromise technique can be of help in selection of the final solution.

\section{Fuzzy compromise selection}

In this method, a value will be attributed to the $i^{\text {th }}$ objective function $F^{i}$ for the $k^{\text {th }}$ solution of the Pareto front as follows:

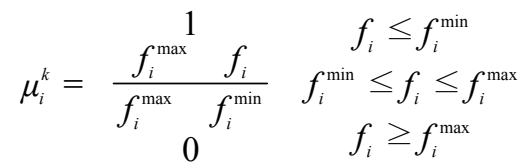

where $f_{i}^{\min }$ and $f_{i}^{\max }$ represent the maximum and minimum of $i^{\text {th }}$ objective function among all Pareto front solutions.

For $k^{\text {th }}$ solution, the fuzzy membership function $\mu^{k}$ can be calculated as follows. The solution with the maximum value of $\mu^{k}$ is the best solution for the problem.

$$
\mu^{k}=\max _{k=1}^{N} \min \sum_{i=1}^{m} \mu_{i}^{k}
$$

\section{SimULATION RESUlTS}

To test the proposed method for optimal placement and sizing of DSTATCOM and parallel capacitors, the IEEE 33node test feeder is employed. The feeder is presented in Fig.4 and its data is taken from [20].
Three different cases are considered. In Case 1 the optimal size and location of DSTATCOM and capacitors are selected by applying the proposed method. In Case 2 only the capacitors size and location are optimized, while Case 3 only considers DSTATCOM. Fig. 5 shows the convergence trend of the employed MPSO algorithm for Case 1. Each axis of the figure is related to one of the considered objective functions. It can be seen that the optimization algorithm is well converged for all objective function. The obtained optimal location and size of the parallel capacitors and DSTATCOM for all three cases are presented in Table. 1.

For Case 1, Fig. 6 shows the network voltage profile before and after installation of parallel capacitors and DSTATCOM at selected locations and with selected sizes. The figure clearly shows the improved voltage profile of the network. Besides the voltage profile, voltage stability was one of the considered objectives. The voltage stability index presented in Fig. 7 indicates the methods success in improving the network voltage stability.

To better highlight the improvements, Table. 2, Table. 3 and Table. 4 compare some of the most common system performance measures for the three cases considered. The results clearly show that in all three cases, the installation of these devices has improved the system performance. However, the installation of both the parallel capacitors and DSTATCOM at selected locations and with selected sizes, has more impact on system performance improvements.

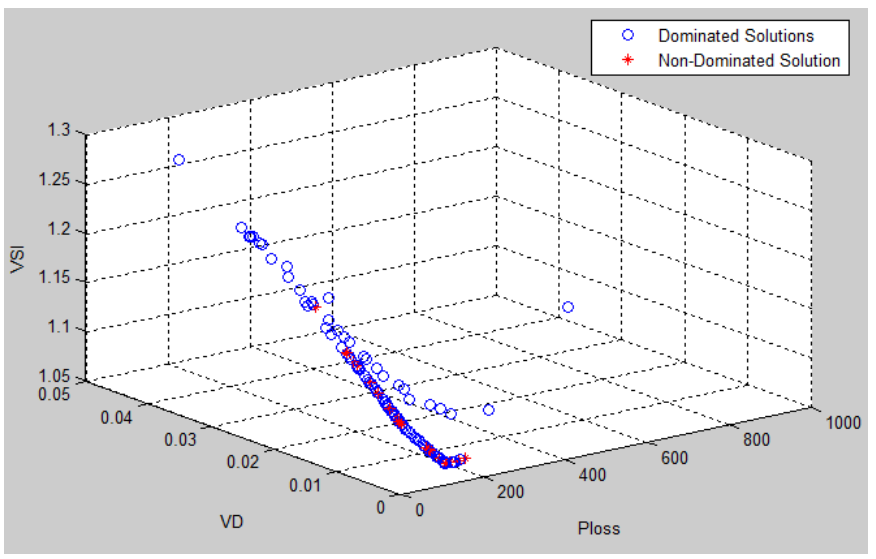

Figure 4. The convergence trend of MPSO for objective functions

TABLE I. THE SELECTED OPTIMAL SIZE AND LOCATIONS OF DSTATCOM AND CAPACITOR BANKS

\begin{tabular}{|c|c|c|c|}
\hline \multicolumn{2}{|c|}{ Optimization results } & Capacitor banks & DSTATCOM \\
\hline \multirow{2}{*}{ Case 1} & Nodes & 7,14 & 30 \\
\cline { 2 - 4 } & Size (KVAR) & 750,450 & 792.48 \\
\hline \multirow{2}{*}{ Case 2} & Nodes & $6,14,29$ & ----- \\
\cline { 2 - 4 } & Size (KVAR) & $300,600,900$ & ---- \\
\hline \multirow{2}{*}{ Case 3 } & Nodes & ----- & 7 \\
\cline { 2 - 4 } & Size (KVAR) & ---- & 1233 \\
\hline
\end{tabular}




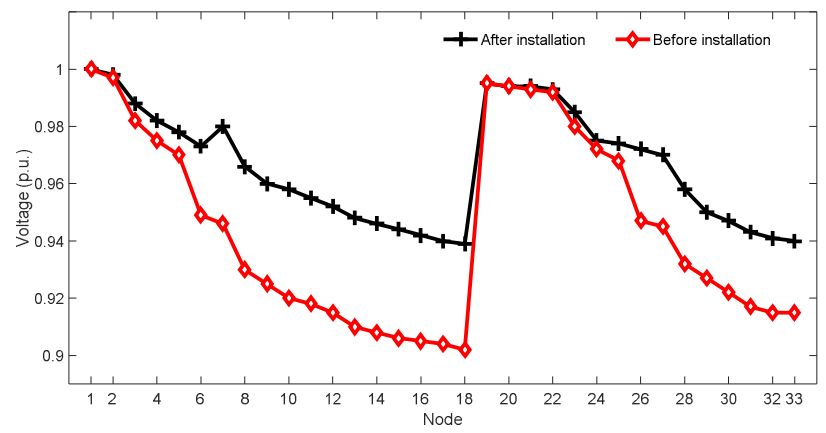

Figure 5. The network voltage profile before and after installation of the parallel capacitors and DSTATCOM

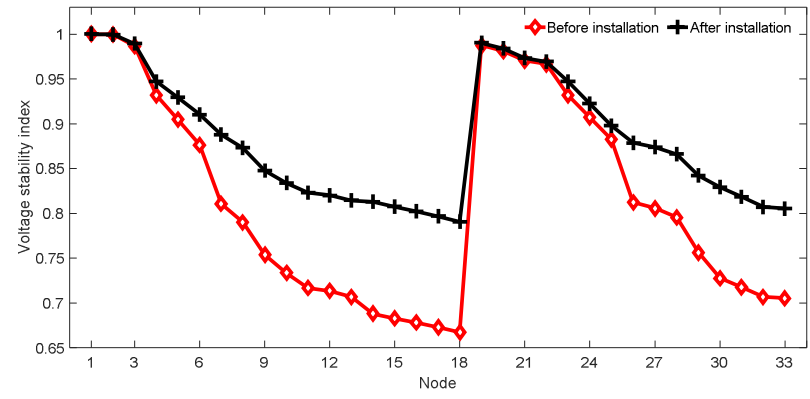

Figure 6. The voltage stability index before and after installation of the parallel capacitors and DSTATCOM

\section{CONCLUSIONS}

The problem of simultaneous optimal placement and sizing of DSTATCOM and parallel capacitors is of considerable importance, considering their ability in improving the networks performance. In this paper, the MOPSO algorithm is employed to solve the problem for a 33node test feeder. The results indicate the applicability and good performance of the proposed method. They show that a combination of parallel capacitors and DSTATCOM has more impact on system performance improvements compared to using each individually. Installation of these devices in selected locations and with selected sizes, satisfies the considered objective functions in terms of decreasing the distribution networks power losses, improving the voltage profile and the voltage stability. Our studies show that the proposed method is fast, flexible and efficient, such that it can be used to simultaneously find the optimal size and location of various devices in distribution networks as a multi objective problem.

\section{REFERENCES}

[1] A. Estebsari, E. Pons, T. Huang and E. Bompard, "Techno-economic impacts of automatic undervoltage load shedding under emergency," Electric Power Systems Research, vol. 131, pp. 168-177, 2016.

[2] A. Ghosh and G. Ledwich, "Load compensating DSTATCOM in weak AC systems," IEEE transactions on Power Delivery, vol. 18, pp. 13021309, 2003.

[3] S. A. Taher and S. A. Afsari, "Optimal location and sizing of DSTATCOM in distribution systems by immune algorithm," International Journal of Electrical Power \& Energy Systems, vol. 60, pp. 34-44, 2014.
TABLE II. THE SYSTEM PERFORMANCE MEASURES BEFORE AND AFTER INSTALLATION OF PARALLEL CAPACITORS AND DSTATCOM (CASE 1)

\begin{tabular}{|c|c|c|}
\hline $\begin{array}{c}\text { Performance } \\
\text { measures }\end{array}$ & Before installation & After installation \\
\hline $\begin{array}{c}\text { Minimum voltage } \\
\text { (p.u.) }\end{array}$ & 0.9038 at node 18 & 0.9392 at node 18 \\
\hline $\begin{array}{c}\text { Maximum voltage } \\
\text { (p.u.) }\end{array}$ & 0.997 at node 2 & 0.9978 at node 3 \\
\hline $\begin{array}{c}\text { Avtive power loss } \\
\text { (Kw) }\end{array}$ & 210.99 & 111 \\
\hline $\begin{array}{c}\text { Minimum voltage } \\
\text { stability index } \\
\text { (p.u.) }\end{array}$ & 0.6671 at node 18 & 0.7902 at node 18 \\
\hline \multicolumn{2}{|c}{} \\
\hline
\end{tabular}

TABLE III. THE SYSTEM PERFORMANCE MEASURES BEFORE AND AFTER INSTALLATION OF PARALLEL CAPACITORS (CASE 2)

\begin{tabular}{|c|c|c|}
\hline $\begin{array}{c}\text { Performance } \\
\text { measures }\end{array}$ & Before installation & After installation \\
\hline $\begin{array}{c}\text { Minimum voltage } \\
\text { (p.u.) }\end{array}$ & 0.9038 at node 18 & 0.928 at node 18 \\
\hline $\begin{array}{c}\text { Maximum voltage } \\
\text { (p.u.) }\end{array}$ & 0.997 at node 2 & 0.996 at node 3 \\
\hline $\begin{array}{c}\text { Avtive power loss } \\
\text { (Kw) }\end{array}$ & 210.99 & 142 \\
\hline $\begin{array}{c}\text { Minimum voltage } \\
\text { stability index } \\
\text { (p.u.) }\end{array}$ & 0.6671 at node 18 & 0.761 at node 18 \\
\hline
\end{tabular}

TABLE IV. THE SYSTEM PERFORMANCE MEASURES BEFORE AND AFTER INSTALLATION OF DSTATCOM (CASE 3)

\begin{tabular}{|c|c|c|}
\hline $\begin{array}{c}\text { Performance } \\
\text { measures }\end{array}$ & Before installation & After installation \\
\hline $\begin{array}{c}\text { Minimum voltage } \\
\text { (p.u.) }\end{array}$ & 0.9038 at node 18 & 0.922 at node 18 \\
\hline $\begin{array}{c}\text { Maximum voltage } \\
\text { (p.u.) }\end{array}$ & 0.997 at node 2 & 0.995 at node 3 \\
\hline $\begin{array}{c}\text { Avtive power loss } \\
\text { (Kw) }\end{array}$ & 210.99 & 153 \\
\hline $\begin{array}{c}\text { Minimum voltage } \\
\text { stability index } \\
\text { (p.u.) }\end{array}$ & 0.6671 at node 18 & 0.726 at node 18 \\
\hline
\end{tabular}

[4] H. B. Tolabi, M. H. Ali, and M. Rizwan, "Simultaneous reconfiguration, optimal placement of DSTATCOM, and photovoltaic array in a distribution system based on fuzzy-ACO approach," IEEE Transactions on sustainable Energy, vol. 6, pp. 210-218, 2015.

[5] B. Weqar, M. T. Khan, and A. S. Siddiqui, "Optimal Placement of Distributed Generation and D-STATCOM in Radial Distribution Network," Smart Science, vol. 6, pp. 125-133, 2018.

[6] M. Kumar, B. Das, M. H. Baloch, P. Nallagownden, I. Elamvazuthi, and A. Ali, "Optimal Placement and Sizing of Distributed Generators and Distributed-Static Compensator in Radial Distribution System: Distributed Generators and Distributed-Static Compensator," International Journal of Energy Optimization and Engineering (IJEOE), vol. 8, pp. 47-66, 2019.

[7] F. Iqbal, M. T. Khan, and A. S. Siddiqui, "Optimal placement of DG and DSTATCOM for loss reduction and voltage profile improvement," Alexandria Engineering Journal, vol. 57, pp. 755-765, 2018.

[8] S. Devi and M. Geethanjali, "Optimal location and sizing determination of distributed generation and DSTATCOM using Particle Swarm Optimization algorithm," International Journal of Electrical Power \& Energy Systems, vol. 62, pp. 562-570, 2014.

[9] M. Farhoodnea, A. Mohamed, H. Shareef, and H. Zayandehroodi, "Optimum D-STATCOM placement using firefly algorithm for power quality enhancement," In IEEE 7th International Power Engineering and Optimization Conference (PEOCO), pp. 98-102, 2013. 
[10] S. S. Hussain and M. Subbaramiah, "An analytical approach for optimal location of DSTATCOM in radial distribution system," In International Conference on Energy Efficient Technologies for Sustainability (ICEETS), pp. 1365-1369, 2013.

[11] A. Jain, A. Gupta, and A. Kumar, "An efficient method for DSTATCOM placement in radial distribution system," In IEEE 6th India International Conference on Power Electronics (IICPE), pp. 1-6, 2014.

[12] A. Bagherinasab, M. Zadehbagheri, S. A. Khalid, M. Gandomkar, and N. A. Azli, "Optimal placement of D-STATCOM using hybrid genetic and ant colony algorithm to losses reduction," International Journal of Applied Power Engineering (IJAPE), vol. 2, pp. 53-60, 2013.

[13] M. Farajzadeh, A. R. Behjou, and M. Novhani, "DSTATCOM allocation considering network reconfiguration using combination of $\mathrm{BB}-\mathrm{BC}$ and GA," In 28th international power system conference, pp. 17, 2013.

[14] T. Yuvaraj, K. Ravi, and K. Devabalaji, "DSTATCOM allocation in distribution networks considering load variations using bat algorithm," Ain Shams Engineering Journal, vol. 8, pp. 391-403, 2017.

[15] R. Sirjani and A. R. Jordehi, "Optimal placement and sizing of distribution static compensator (D-STATCOM) in electric distribution networks: A review," Renewable and Sustainable Energy Reviews, vol. 77, pp. 688-694, 2017.

[16] M. Chakravorty and D. Das, "Voltage stability analysis of radial distribution networks," International Journal of Electrical Power \& Energy Systems, vol. 23, pp. 129-135, 2001.

[17] P. N. Vovos and J. W. Bialek, "Direct incorporation of fault level constraints in optimal power flow as a tool for network capacity analysis," IEEE Transactions on Power Systems, vol. 20, pp. 2125$2134,2005$.

[18] A. Bahmanyar, A. Estebsari, A. Bahmanyar, and E. Bompard, "Nonsy load flow: Smart grid load flow using non-synchronized measurements," In IEEE International Conference on Environment and Electrical Engineering and IEEE Industrial and Commercial Power Systems Europe, pp. 1-5, 2017.

[19] C. A. Coello Coello, G. Toscano Pulido, and M. Salazar Lechuga "Handling multiple objectives with particle swarm optimization," IEEE Transactions on evolutionary computation, vol. 8, pp. 256-279, 2004.

[20] M. Baran and F. F. Wu, "Optimal sizing of capacitors placed on a radial distribution system," IEEE Transactions on power Delivery, vol. 4, pp. 735-743, 1989 